EL NECESARIO PROTOCOLO

\section{EN LA COMUNICACIÓN}

ORGANIZACIONAL

\section{Dr. Julio César Herrero}

\section{Doctor en Ciencias de la Información \\ Facultad de Ciencias de la Comunicación. Universidad Camilo José Cela. Castillo de Alarcón, 49. Urb. Villafranca del Casti- llo, Villanueva de la Cañada, 28692 Madrid (España) - Tlfn.: (+34) 918153131 - Email: jcherrero@ucjc.edu}

\section{Gloria Campos García de Quevedo}

\section{Directora General de Formación}

Escuela Internacional de Protocolo. C/ Plaza de Santa Bárbara, 9, 1․ 28004, Madrid (España) - Tlfn.: (+34) 627541060 - Email: glorialprotocolo.com

\section{Resumen}

El protocolo se ha convertido en una herramienta estratégica de comunicación de las empresas, tanto a nivel interno y corporativo como en su proyección externa. El protocolo se encuentra también entre una de las posibles acciones estratégicas para reforzar la reputación corporativa. Este trabajo examina cómo los actos comunican, trasladan la imagen y estilo y responsabilidad social corporativa de una organización, permiten la interrelación con los stakeholders y generan experiencia, superando algunas de las acciones tradicionales de comunicación en el ámbito empresarial y/o institucional.

\section{Palabras clave}

Comunicación, protocolo, actos, relaciones institucionales, organización, relaciones públicas, responsabilidad social corporativa

Key Words

Communication, protocol, events, institutional relationships, organization, public relations, corporate social responsibility

\section{Abstract}

Protocol has become a strategic tool in corporate communication, as much internally as within the image it sends out to the world. Protocol also is important in regards to possible strategic actions taken to reinforce the reputation of a corporation. This work examines how corporate functions communicate and represent the image, style, and social responsibility of an organization as well as permit positive relations with the stockholders, improving some of the traditional actions of communication en the business and institutional world. 


\section{Introducción}

El concepto de 'protocolo' ha ido evolucionando en los últimos años desde una perspectiva más clásica, entendida exclusivamente como una técnica al servicio del marketing o de la comunicación - pero auxiliar o secundaria, en todo caso-, a un planteamiento más complejo, convirtiéndose en eje, en algunos casos, de las estrategias de comunicación diseñadas por empresas o instituciones. La gestión integral de un acto "ha hecho que el tradicional triángulo de la organización se nos antoje ya algo del pasado" (Fuente, 2007). La producción, la creatividad, las tecnologías, son elementos que se han ido sumando a la visión primigenia de la organización de actos, que se sostenía sobre el protocolo, la seguridad y la comunicación.

La Responsabilidad Social Corporativa (RSC) de las empresas encuentra en el protocolo moderno una de las herramientas para visualizar su actividad en la sociedad en la que se desenvuelve. Pero las acciones de comunicación no se desarrollan sólo hacia fuera para afianzar su reputación y conseguir captar el interés de los medios, sino también hacia los públicos internos, en un intento por afianzar la filosofía de la organización. El protocolo se convierte, así, en un elemento indispensable para la comunicación externa e interna. Como indica Manuel Martí:

"si las instituciones o las grandes corporaciones desean mantener el protocolo más como imagen de la organización que como espacio de comunicación y participación con sus públicos, pueden perder información para hacer más eficaz el acto de protocolo y conocer las vías de su mejora y desarrollo" (Martí, 2008).

\section{Objetivos}

Demostrar que el triángulo clásico (protocolo, comunicación y seguridad) está superado tanto en la literatura científica como en la práctica de las organizaciones.

Analizar cómo la gestión de la imagen en las organizaciones debe ser entendida en un sentido amplio, hacia fuera (comunicación externa), pero también hacia adentro (comunicación interna).

Establecer la vinculación existente entre el protocolo y el marketing presencial, entendido éste como una evolución de las formas tradicionales de publicidad. 


\section{Metodología}

Para la redacción de este trabajo se ha realizado en primer lugar una revisión bibliográfica de la literatura científica en materia de protocolo. Posteriormente, se analizaron cuatro actos de comunicación corporativa desarrollados por la cadena de televisión Cuatro y la constructora Case (comunicación externa), y las empresas BMW y Telefónica (comunicación interna) que permiten ejemplificar las propuestas teóricas expuestas.

\section{Una revisión conceptual del término 'protocolo'}

El protocolo está considerado como una importante herramienta de comunicación estratégica, aunque todavía exista una gran discrepancia e incluso contradicciones entre los especialistas que han teorizado a partir de la segunda mitad del siglo XX sobre su significado. La evolución del concepto ha sido vertiginosa en los últimos años. Carlos Fuente (2007) afirma que:

Frente al Protocolo de ayer, aquél que pretendía reflejar el poder de las autoridades, su fortaleza frente al mundo y la sociedad mediante un pomposo ceremonial y una rígida etiqueta (caso de los Reyes Católicos y la dinastía de los Austrias en España o la borgoñona en general, o los primeros reyes borbones de nuestro país), surge hoy un nuevo Protocolo que pretende alcanzar, armoniosamente, una buena organización y trasmitir comunicación cuando el acto es pensado para llegar más allá del mero foro de invitados presentes. La existencia de los medios de comunicación, sus nuevas y sofisticadas tecno-

\begin{abstract}
logías, su capacidad de inmediatez y registro de los más pequeños detalles, ha obligado a concebir las técnicas de protocolo y ceremonial de forma muy diferente. Este cambio es espectacular desde los años ochenta, siendo realmente importante la influencia periodística en la forma de concebir y resolver cualquier tipo de acto público.
\end{abstract}

María Teresa Otero (1999), en su tesis doctoral que sirvió de base para su libro Teoría y Estructura del Ceremonial y el Protocolo, mantiene que "se impone definitivamente el término protocolo, que pierde su sentido original (en realidad, el último de ellos cronológicamente) y cuyo ámbito semántico se extiende y amplía a otros campos (la empresa, el deporte, la universidad, etc.), aglutinando etiqueta, urbanidad, usos sociales, etc.”. El trabajo bibliográfico de M ${ }^{a}$ Luz Álvarez (2008)

También nos ha mostrado la existencia de tres perspectivas teóricas muy marcadas en 
las diferentes autoridades a través de sus definiciones. Todos los conceptos analizados están pensados bajo alguna de estas tres perspectivas: histórica, jurídica y comunicológica; lo que indica un intento de reflexión epistemológica e investigadora en torno a la materia, así como un ordenamiento del conocimiento en cuatro cuerpos doctrinales, de mayor o menor contenido teórico que podemos denominar escuelas.

Otero llega incluso a establecer en las conclusiones de su tesis doctoral diferentes escuelas según el tipo de definición. Así, habla de la escuela tradicional diplomática (poniendo como referentes a Serres, Gandouin, Urbina, Tristany), el derecho (Francisco López-Nieto, Camilo López), la historia (Joaquín Martínez-Correcher, Felio A. Vilarrubias, Mauricio Domínguez Domínguez-Adame), la antropología (Miguel Ángel Radic) y la comunicación (José Pumar, José Pablo Arévalo García-Galán, Jorge Blanco Villalta, Noguero, Carlos Fuente, Juan José Laforet o Francisco Marín Calahorro). Otras tesis doctorales españolas sobre protocolo, en concreto la de Salvador Hernández (2006), Javier Sierra (2007) y la de la propia María Luz Álvarez (2008), insisten en la extensión a otros campos de la definición de protocolo, su relación con otras disciplinas transversales y su clara vinculación a la comunicación.

En definitiva un concepto donde la organización está al servicio de unos objetivos, de la finalidad del acto y de los mensajes que se pretenden transmitir. Un protocolo que flexibiliza las precedencias y las normativas vigentes, así como los usos y costumbres tradicionales, y que valora singularmente la comunicación. Alfredo Rodríguez (2005) señala que "cuando alguien se encarga de organizar un acto, su misión es que todo salga de acuerdo a lo programado, que la imagen sea la adecuada y que el final resulte armonioso. Para ello, ha de contar con los conocimientos y recursos adecuados, tanto humanos como materiales, y debe seguir las directrices legales y del anfitrión u organizador del acto”.

En la actualidad, y según Fuente (2007), "la gestión integral de un acto, que conlleva ocuparse de otros factores adicionales de la organización, tales como la producción, la creatividad o el equilibrio presupuestario (por no señalar otros aspectos relacionados con otras disciplinas próximas como el marketing comercial o político o institucional) ha hecho que el tradicional triángulo de la organización se nos antoje ya algo del pasado". Este autor, artífice de la teoría de la diana en cuyos círculos concéntricos se sitúan la creatividad, la comunicación, el protocolo, la producción y la seguridad. Una visión que indica que lo más importante es tener una buena idea del acto, teniendo en cuenta los objetivos y la comunicación (a quién se quiere transmitir), programarlo correctamente (el protocolo), darle la forma adecuada (la producción), salvar las barreras y establecer las garantías de protección integral de las personas (la 
seguridad) y gestionar adecuadamente el dinero (el presupuesto).

Otros autores también señalan la importancia de la producción, la creatividad, las tecnologías, la seguridad y por supuesto la comunicación. José Pumar (1995) vincula el Protocolo de Estado como emisor de comunicación: "El Protocolo debe ser fiel reflejo del orden que debe presidir todo acto para que dé una imagen de prestigio de la propia Corporación”. Francisco Marín Calahorro va más allá:

El Protocolo, instrumento que ordena los actos, forma parte de las estrategias y tácticas de la comunicación institucional, así como de la corporativa y de las organizaciones. En primer lugar, porque todo ceremonial constituye, en las diferentes culturas, una pauta para la puesta en escena de interacciones comunicativas revestidas de rango social; $y$, en segundo lugar, debido a que, en la actividad social de instituciones/corporaciones y organizaciones, son imprescindibles determinadas interacciones comunicativas que requieren una cuidada escenificación para conseguir un reconocimiento social que facilite la creación de una identidad en la percepción colectiva, acorde con objetivos definidos previamente.

Existe un notable consenso entre los autores consultados al establecer que el protocolo es un conjunto de normas, tradiciones y técnicas mediante las cuales se regulan y planifican los actos promovidos por las instituciones públicas, entidades privadas y por las personas, se establece su orden y desarrollo, y se ordenan los invitados y los símbolos. Además, como indica Fuente (2007), es la "profesión que se ocupa de la organización de actos que afectan a las instituciones, entidades y personas, de la aplicación de las normas y tradiciones vigentes en este campo y de su ceremonial”.

En nuestra opinión, el protocolo ha recobrado en la sociedad actual un papel importante y en muchos casos, protagonista tanto en las instituciones públicas como en las entidades privadas, especialmente, en el campo de la preparación de los actos internos y externos, y en la imagen final de la institución. El protocolo se presenta también como una disciplina de suma importancia en las relaciones institucionales e internacionales, convirtiéndose en el elemento vertebrador de las relaciones entre partes y su puesta en escena para hacer posible la consecución de los objetivos institucionales y empresariales que se determinen en cada caso.

Fuente (2007) afirma que "hoy entendemos como acto o evento (expresión que autoriza actualmente la RAE) al desarrollo de una función o representación destinada a cumplir los objetivos por los que se promueve y que se dota del ceremonial adecuado. Consta habitualmente de cuatro partes: un inicio o bienvenida, un desarrollo del objetivo central del mismo, un encuentro de carácter social y una despedida”. Participando de esta afirmación consideramos que cuando hablamos de protocolo, hablamos 
de la organización de actos, tanto oficiales, como no oficiales.

La comunicación corporativa hace referencia a la gestión estratégica de la comunicación interna y externa para crear unas relaciones entre los públicos que redundan en la imagen y reputación corporativa de la organización. Ahora bien, si no hay acciones adecuadas, la imagen ante sus públicos interesados o stakeholders considerados por Freeman (1985) como un elemento esencial en la planificación estratégica de los negocios, tendrá unos efectos contrarios sobre dicha reputación corporativa.

Mínguez (1999) afirma que "la imagen debe gestionarse en todos los niveles de la organización y en todas las áreas de su actividad, pues el comportamiento de la empresa, cada acto de cada uno de sus empleados, tiene un efecto en su imagen global". Todo no comunica por sí mismo, hay que acompañarlo de acciones y compromisos, de principios éticos para que tenga repercusión en la reputación de la organización. El protocolo se encuentra entre una de las acciones estratégicas para reforzar la reputación corporativa. Los actos comunican, trasladan la imagen $\mathrm{y}$ estilo y responsabilidad social corporativa de una organización, permiten la interrelación con los stakeholders, generan experiencia y esto es algo que lo convierte en herramienta estratégica en la comunicación organizacional.

\section{Los actos, herramientas estratégicas de comunicación}

El panorama mediático mundial y la trascendencia de la comunicación global en cualquier aspecto de la sociedad, hacen que una correcta planificación estratégica de los actos se considere de tanta trascendencia como una buena estrategia con los medios de comunicación o una correcta planificación técnica del desarrollo y estructura del acto.

Los actos son utilizados por los organismos públicos y privados como un instrumento de proyección (interna y externa) de imagen y de reputación corporativa y como herramienta estratégica de comunicación, marketing y publicidad. Pero no queda sólo ahí: a través del protocolo, de las relaciones institucionales y de los actos empresariales y corporativos, se puede mostrar una radiografía de las organizaciones y sus interrelaciones, mediante una cuidada puesta en escena no exenta de complejos planteamientos técnicos y artísticos como contenedores de los mensajes y valores que se quieren trasladar.

Organizar actos como instrumento de comunicación y de reputación corporativa debe concitar los esfuerzos de una adecuada planificación estratégica; del desarrollo 
óptimo de las necesarias relaciones institucionales y, por ende, adecuadas técnicas negociadoras; del conocimiento de la normativa legal o estatutaria y reglamentada de las distintas instituciones y organizaciones, sus estructuras y características, tanto en el plano nacional como internacional; del planteamiento y aplicación exitosa del plan de comunicación que se haya establecido; de la adecuada elección de tecnologías necesarias; de las soluciones escenográficas más oportunas; del diseño de una producción impecable tanto en lo técnico y logístico como en el cumplimiento riguroso de la normativa establecida, la seguridad y las homologaciones pertinentes; del conocimiento de todos los actores que intervienen en los actos, sus relaciones y su representación.

Por otra parte, el agotamiento de tradicionales fórmulas publicitarias y la necesidad de nuevas estrategias de marketing están provocando que muchas empresas consideren el acto como una herramienta de marketing que, además, es estratégica y por tanto parte de los planes anuales de marketing de muchas empresas. El estudio "Situación y tendencias en el mercado español de actos”, considerado como el libro blanco del sector de actos y realizado por el Grupo Acto Plus en 2007, el mercado español de actos representa más de 5.000 millones de euros. Según ese informe, las empresas españolas destinan el 18\% de sus presupuestos de marketing a la organización de actos (2.600 millones de euros). A esta cifra conviene añadir los actos de asociaciones (más de 1.450 millones) y los actos internos de empresas (1.200 millones).

Según este estudio, los actos se han consolidado como una herramienta de marketing muy válida para las empresas y se prevé que siga este desarrollo. Así, el 46\% de las empresas españolas prevé que el presupuesto en actos aumente más del $5 \%$ durante los próximos tres años; mientras que tan sólo un $8 \%$ prevé que bajará. El 37\% estima que se mantendrá estable.

El acto más utilizado por las empresas son las ferias (con el 65\% de participación), seguido de las convenciones (55\%) y las presentaciones de productos (47\%), tres tipologías que requieren una interrelación con sus públicos, y por tanto una adecuada estrategia de comunicación.

Las empresas automovilísticas ya no vende coches sino "placer de conducir"; las marcas deportivas de primer nivel tampoco venden zapatillas y vestuario deportivo, sino "pasión por el deporte"; las empresas de informática ya no solo venden hardware y software, ahora ofrecen experiencias únicas con los ordenadores; y las cerveceras quieren ser algo más que cerveza y por ello se entregan a proyectos como festivales de música (Heineken Jazzaldia de San Sebastián, el FBI Heineken) o patrocinios como la Liga de Campeones, realizando unas estrategias que acerquen al consumidor a la marca a través de experiencias y vivencias que conectan perfectamente con su público. 


\section{El protocolo en la comunicación externa: el marketing de experiencias}

Con la resaca del triunfo de España en la Eurocopa 2008, muchas marcas vendieron a través de distintos formatos y estrategias su vinculación con la Eurocopa y con la selección española: coches, restaurantes, cervezas, marcas deportivas, refrescos, periódicos, bancos..., un sinfín interminable de patrocinadores que mostraron su apoyo incondicional, porque todos ellos son conscientes del valor mediático que genera un acto de tales dimensiones, pero sólo algunas compañías se fijaron en el alto valor emocional que suscita dicha competición. La cadena televisiva Cuatro desplegó una estrategia que tras el eslogan "Podemos” ofrecía en cada partido de la selección española una experiencia que vinculaba las emociones y sentimientos de la competición, a su cadena. La denominada "Plaza Roja”, la Plaza de Colón de Madrid, se convirtió en el espacio que la cadena televisiva ofrecía a los espectadores para vivir de forma conjunta cada partido, y para ello creó un gran plató televisivo por donde comentaristas, presentadores, artistas, famosos, conectaban con ese público que, a través de grandes pantallas gigantes y en directo, vivían una jornada inolvidable. Eran parte de una emoción que contagiaba al país y nos acercaba a la "plaza roja" a vivir la experiencia y a participar de forma indirecta en la pasión. Cuatro optó por un acto de experiencia, una acción que mira la calidad del impacto. De hecho, la maquinaria puesta en marcha por la cadena de televisión caló tanto en la población que, cuando hubo que organizar un acto institucional por la celebración de la victoria española en el campeonato, las instituciones públicas y la propia Real Federación Española de Fútbol tuvieron que improvisar un nuevo escenario muy cercano al de la cadena, en la misma plaza para que, por una parte, se separara la parte "oficial" de la "comercial", diferenciando así el origen de cada iniciativa y se pudiera retransmitir a través de una señal institucional la victoria nacional pero, a la vez, manteniendo el público congregado, ya acostumbrado a visualizar y celebrar cada partido en la Plaza de Colón.

En estos casos, el acto se convierte en nuevo producto que hay que comunicar porque materializa la marca a través de una experiencia que es vivida por un número de personas y comunicada a millones. En este contexto las marcas buscan medios que les permita conectar con millones y que causen un gran impacto $\mathrm{y}$, además, distinto a esos miles de impactos que recibimos cada día a través de la publicidad. Como afirma Campos (2008) "el acto puede conseguir esta comunicación e impacto porque lo hace a través de múltiples canales y ex- 
periencias vivenciales, con los cinco sentidos, mediante audiovisuales, espacio, aromas, texturas, actividades, comida, decoración, música, etc.”

El acto permite captar la atención del público directamente y durante más tiempo que la publicidad además de crear un marco para el contacto directo y la interrelación. La experiencia genera un recuerdo mucho mayor en su intensidad y más duradero que otros medios, lo que lo convierte en la actualidad en punto de mira y de interés de importantes marcas. Ahora bien, todas estas bondades que le otorga el marketing se volverían en contra si el acto no está bien y profesionalmente organizado.

Las empresas e instituciones demandan actos que propicien una comunicación más eficaz, optimicen resultados y causen impacto. Estas exigencias están provocando el desarrollo de nuevos formatos de actos, casi tantos como los que se realizan, porque son actos a medida, pensados para satisfacer las necesidades y expectativas del cliente y alcanzar los objetivos planteados.

Observamos que en el contenido de gran parte de los actos se mezclan diversas finalidades, promocionales, institucionales, culturales, etc., aunque la tendencia actual refleja una serie de factores comunes que determinan el contenido de los actos que responden a estas nuevas exigencias.

- El valor de la creatividad, la capacidad para desarrollar una idea sobre la que diseñar el acto, su programa y con- tenido, que responda sus objetivos, incluso que genere la propia necesidad de llevar a cabo el acto, que sea impactante (en el sentido de originalidad y singularidad) y que la diferencie del resto de actos. Una idea sobre la que trazar un esbozo que cuide al detalle cada parte, que mime a sus invitados, que genere sensaciones y que, además, sea interesante y mediática.

- La importancia del protocolo en todo el proceso organizativo y en la ejecución del acto, un protocolo estratégico en su planificación y más humanizado en su desarrollo y ejecución. Creatividad y protocolo unidos a una exquisita puesta en escena, con elementos de construcción escenográfica adaptados a dicha idea, que cobren vida por sí mismo, que refuercen el mensaje corporativo y/o institucional, que tenga brillo y nos arrope con su ambiente.

- Una escenografía que conforme espacios poco saturados y con armonía en sus colores, donde la gráfica corporativa y las nuevas tecnologías cobran muchísima fuerza. Escenografías efímeras en la mayor parte de los casos, porque cada acto es diferente.

- Una adecuada producción, montajes sencillos o complejos, pero con una buena iluminación y sonorización, tecnologías punteras, soluciones técnicas de alta calidad, con estructuras y montajes de primer nivel. 
- Actos que comuniquen, que eliminen barreras, que incorporen a las sensaciones a los públicos a los que van dirigidos y trasladen los mensajes y objetivos del acto, que interrelacionen al público con la empresa, institución, producto...y nos aproximen a ellos. Esto significa actos más rítmicos y visuales, nada encorsetados, con pocos parlamentos o parlamentos cortos, claros y sencillos en sus mensajes, y por supuesto interesantes para los medios de comunicación.

- La seguridad es un factor de suma importancia. No nos referimos sólo a evitar actuaciones hostiles, sino también a la seguridad en su conjunto, de las instalaciones, de los recorridos, de los montajes, etc.

- Innovación mediante la utilización de una tecnología vanguardista e innovadora.

- Preocupación por la sostenibilidad. Es una de la tendencias más valoradas en la actualidad, que el contenido y la puesta en escena de los actos contemple la Responsabilidad Social Corporativa (RSC), entendida como aquellas obligaciones o compromisos derivados del impacto que la actividad empresarial tiene en la sociedad en la que se desenvuelve. Actos que apuesten por la sostenibilidad de nuestros recursos y adopten prácticas que contribuyan a ello.

- Espectáculo y actividades de animación dentro de los actos y como parte de su contenido, sobre todo en los actos empresariales, aunque no es extraño contemplar un espectáculo de acrobacia aérea durante la conmemoración del Día de las Fuerzas Armas o en otros actos promovidos por las instituciones públicas.

Junto a estos factores, observamos también que la combinación de distintas actividades de ocio con formación o presentación de un producto es también otra de las tendencias actuales, al igual que dividir el acto para reducir el número de participantes y poder, de esta forma, establecer una relación más directa con el invitado. Ejemplos como el siguiente ilustran la reflexión realizada.

La compañía Case Construction, perteneciente a la multinacional $\mathrm{CNH}$ del grupo FIAT, organizó en Valencia, en junio de 2007, el lanzamiento de sus nuevas excavadoras. Según la propia compañía bajo el lema de 'Pasión en Movimiento' nació la nueva CASE. Para celebrarlo, más de 750 personas se dieron cita en junio de 2007 en Valencia, para conocer los nuevos productos. La nueva serie de excavadoras de cadenas $\mathrm{CXB}$, las nuevas cargadoras de ruedas de la serie E y la nueva mini cargadora de cadenas $440 \mathrm{CT}$. Las principales novedades se exhibieron en un espectacular encuentro donde la empresa se convirtió en el centro de la Ciudad de las Artes y las Ciencias.

El acto se celebró en tres escenarios diferentes (La Ciudad de las Ciencias y las 
Artes, L’Oceanografic y la cantera Hermanos Andújar y Navarro), y fue dirigido al siguiente público: red de concesionarios, clientes y prensa especializada nacional e internacional. Se trataba por tanto de realizar un acto cuya historia argumental interesara a los tres grupos de público al que iba dirigido. El primer día se realizó un tour por la ciudad, visitando la dársena donde tuvo lugar la America's Cup y donde los directivos de la compañía pudieron interactuar, relacionarse y comunicarse de forma directa con su público, añadiendo el valor de la comunicación cara a cara. Por la tarde se llevó a cabo la presentación del producto en L'Oceanogràfic, con la participación del equipo directivo español y del vicepresidente europeo de Case. Tras esto, una breve visita en La Ciudad de las Ciencias y las Artes de la exposición de los nuevos productos y degustación de un cóctel ambientado por un grupo de jazz en directo. Una cena en L'Hemisfèric donde tuvo lugar un espectáculo, que incluyó el 'reveal' de los productos y la interacción con la maquinaria puso fin a la jornada. El segundo día se acercaron de forma tradicional a la marca, en la cantera de Paterna, corporativizada de "ciudad Case" para la ocasión, donde probaron las novedades del producto.

El acto mezcló varios formatos: presentación de producto, acto institucional y de motivación, espectáculo, acto social y contacto directo con el producto. Pero, sobre todo, fue diseñado pensando en cada momento en el público al que iba dirigido, sus gustos, aficiones compartidas, tipología del grupo..., para realizar un programa con nexos en común con sus inquietudes, intereses y forma de ser y su relación con la empresa. Trabajar y divertirse, generar "pasión” a través de la revalorización del equipo humano de la empresa y de sus clientes y mirando al futuro, en movimiento y con fuerza. Un programa que, al margen del espectacular montaje, cuidaba los detalles y el mimo a los invitados.

Durante todo el acto, la marca siempre estuvo presente, a lo largo de los distintos trayectos que recorrieron, en las paradas, en el acto institucional, mediante gráfica $\mathrm{o}$ luces, incluso entre tiburones...y la visión del producto permanentemente asociada a ligereza, movilidad en contraposición con la sensación de robustez que nos viene a la cabeza cuando pensamos en una gran excavadora. En el acto institucional los directivos sólo tenían como apoyo un atril y micrófono inalámbrico para recorrer el escenario; mensajes bien estudiados y gestos que revalorizan los recursos humanos, su entrega, la grandeza del trabajo realizado, el reconocimiento a los invitados y su colaboración con la empresa, las previsiones.... Y un gran montaje técnico que arropaba todos los mensajes sin restarles protagonismo, porque la escenografía para este acto era de gran sencillez, aunque técnicamente compleja, grandes pantallas de retro proyección como único decorado. Sobre ellas se fueron proyectando los dis- 
tintos eslóganes de la campaña. El escenario, vacío: solo un atril que quedaría desplazado en el momento más álgido por el equipo humano de la empresa.

En el espectáculo no faltó un gran despliegue de medios técnicos y audiovisuales (innovación) para reflejar la 'pasión en movimiento', consiguiendo una simbiosis entre artistas que parecían volar, dotados de una gran flexibilidad y calidad interpretativa, con las excavadoras que aparecen en el escenario como por arte de magia, conectando así con la idea de movilidad y ligereza, generar en definitiva una experiencia cuyo recuerdo permanezca $y$, además, refuerce los mensajes de la bondad del producto que se presenta.

Finalmente, una visita a las canteras y una demostración in situ. Los invitados podían ver en directo el funcionamiento del producto, incluso experimentarlo. Para los más atrevidos, la vista vertical subidos en un globo aerostático. Y como conclusión a las dos jornadas, un encuentro para degustar una paella y despedirse en un ambiente más informal, fomentando el contacto interpersonal.

Como vemos, formatos a medida y actos muy cuidados y cuyo contenido seduzca, generen el recuerdo provocando reacciones inesperadas, sorprenda, por su buena organización, por el montaje realizado, por su armonía, por el equilibrio de todas sus partes, por el cuidado a los invitados... En definitiva, por las ideas que han hecho posible un perfecto engranaje de todas las piezas, convirtiendo el acto en una experiencia que no caerá en el olvido. Esto es comunicación estratégica.

Parece evidente que los actos tienen un gran poder de comunicación. Pueden transmitir desde el estilo de la empresa y sus valores a la eficacia de un producto. Para ello debe tenerse en cuenta los siguientes aspectos:

- Los actos empresariales deben huir de ceremonias engorrosas y efímeras y alejarse del tradicional carácter oficial de los actos.

- Deben transmitir el valor diferencial con respecto a otros competidores.

- Deben trasladar imaginación. Una empresa imaginativa es una empresa que transmite futuro, adaptación a los tiempos, inquietud positiva, acercamiento.

- Los escenarios adquieren una gran importancia. Con formas, materiales, texturas, colores, olores, creamos espacios de comunicación. Escenarios versátiles y moldeables, con una tendencia clara hacia el minimalismo, accesibles, con armonía cromática, sencillos y mediáticos cuando deban serlo.

- Los actos deben comunicar por sí mismos y conseguir la prolongación temporal en la eficacia comunicativa $y$ promocional.

En definitiva actos diseñados en torno a las siguientes variables: 
- Fidelización: mediante el recuerdo durante y después del acto.

- Emoción: generar el recuerdo provocando reacciones inesperadas.

- Innovación: una tecnología vanguardista e innovadora.
- Rentabilidad: actos enfocados a la eficacia de los resultados.

- Comunicación: un enfoque estratégico que permita obtener una comunicación 100\% eficaz, que hará que el público no olvide fácilmente la marca.

\section{El protocolo en la comunicación interna}

Veamos ahora la importancia de los actos en la comunicación interna de las organizaciones. Mercedes Benz organizó en enero de 2008 una gran gala que, bajo el título "La noche de las estrellas", fue diseñada para premiar el record de ventas. 600 personas pertenecientes a la red comercial y directivos de la compañía participaron en esta noche especial celebrada en el Palau de les Arts Reina Sofía (Ciudad de las Artes y de las Ciencias de Valencia) dentro de la convención anual de comerciales y bajo la organización técnica de la agencia Grupo Eñe. El impresionante Palau de les Arts con aproximadamente 37.000 metros cuadrados de superficie y 70 metros de altura se vistió de gala en una "noche estrellada” en la que un espectáculo de luces transformó el espacio en un universo de estrellas y fuegos artificiales.

El objetivo del acto consistía en motivar a los vendedores de una manera diferente, divertida y amena durante un día. El mensaje debía conjugar el reconocimiento / homenaje con la marca y, a su vez, hacer sentir a los comerciales como estrellas de Hollywood, como los mejores entre los más buenos. El concepto argumental del acto se basaba en el lema "Sois los mejores" y en un guiño al famoso logo de la compañía (la estrella de Mercedes) combinado con el mundo de la celuloide. La gala se tituló "La noche de las estrellas de Mercedes Benz”. En principio se pensó como lema "Eres el mejor". Sin embargo la compañía quería resaltar el trabajo de equipo, el esfuerzo conjunto de los recursos humanos implicados.

Los actos de motivación y refuerzo en sus múltiples versiones están adquiriendo una gran importancia en las empresas. Organizar un acto donde la motivación es el eje principal de su objetivo se ha convertido en un valor en alza puesto que aporta, además, otros contenidos y mensajes que tratan de fidelizar a los empleados. Son actos que hay que cuidar y en los que el invitado es el verdadero protagonista. En este caso los invitados pertenecían a la red de ventas de Mercedes Benz, un público muy heterogé- 
neo, de distintos ámbitos geográficos, mayoritariamente masculino y con distintos niveles formativos.

A la llegada a los hoteles, los protagonistas encontraban mesas de acogida o recibimiento donde podían recoger su documentación, una pequeña carpeta que contenía la tarjeta llave de la habitación (todas eran diferentes), las acreditaciones y 'roll-ups'. Cada invitado pudo encontrar en sus habitaciones su propia estrella personalizada y mensajes en los espejos que recordaban el reconocimiento de la compañía al esfuerzo realizado. Sobre los espejos, cristales y mamparas de los cuarto de baños se pegaron seductores vinilos donde un dibujo representaba el beso de un labio con carmín rojo acompañado del lema de la gala provocando una reacción de sorpresa y satisfacción a cada uno de los invitados.

Un servicio de autobuses recogió a los invitados en el hall del hotel para trasladarlos hasta la alfombra roja que decoraba el suelo del lugar, desde las primeras escaleras hasta la entrada del recinto. Nada más bajar del autobús, un grupo de fans, controladas por un falso cordón policial, con carteles con la estrella de Mercedes Benz y con la frase "Sois los mejores", recibían a los invitados con aplausos y vítores. Falsos fotógrafos y reporteros con cámaras de televisión iban grabando la llegada. Los 'periodistas' simulados realizaban preguntas del tipo “¿cómo se siente al ser una estrella de Mercedes Benz?” a unos asombrados protagonistas. Las puertas del audi- torio daban paso a un espacio transformado, mediante un elaborado juego de luces, en un universo de estrellas y fuegos artificiales, ambientado también por el sonido de una música tecnológica que reforzaba el universo recreado con la iluminación que, además, se mantuvo durante todo el acto.

Una vez acomodados todos los invitados, una voz en off dio la bienvenida a los asistentes. De forma inmediata se proyectó un vídeo corporativo y editado para esta ocasión con el título de "Pasado, Presente y Futuro”. La presentadora, la modelo Remedios Cervantes, condujo el resto de la gala e interactuó con los asistentes durante toda la presentación para hacerla más viva y dinámica. El presidente de Mercedes Benz que, al igual que el resto de invitados, vestía un atuendo informal, intervino breves momentos y dio paso a los vídeos que se alternaban con comentarios de ellos y cuyo contenido reforzaba la fuerza de las ventas y del equipo humano que lo hizo posible. Los vídeos, editados a modo de un informativo de televisión mostraban noticias sobre las hazañas conseguida por la red comercial, porque la idea de otorgar todo el protagonismo a los vendedores y concesionarios estuvo presente en cada momento de la gala.

Las pantallas iban reproduciendo los simulados telediarios con entradillas espectaculares, como "Mercedes Benz ha batido su record...", "pon una furgoneta en tu vida", ese debe haber sido el lema de la población este año porque gracias a Mercedes Benz 
millones de ciudadanos ya cuentan con su vehículo industrial”, "Mercedes Benz llega a lo más alto", "Los vehículos industriales de Mercedes Benz van sobre ruedas" ó "Mercedes Benz no sólo ha alcanzado sus objetivos este año, sino que los ha superado. Enhorabuena Mercedes Benz". Tras los 'informativos' se produjeron otras intervenciones a cargo de directivos de la compañía con pinceladas sobre objetivos y estrategias para el año 2008 y trasladando mensajes motivadores a un auditorio que, según pasaban los minutos, se iba entregando cada vez más.

Homenajear a los empleados que han hecho posible el récord de ventas fue otro de los retos planteados. Decidir dar nombres, personalizar con los riesgos que conlleva o realizar algo en el que todos quepan. Finalmente, la agencia optó por un vídeo lleno de emotividad en el que se intercalaban distintas imágenes de los comerciales en diversos ambientes. El texto de un poema de Kipling era la línea argumental del vídeo reforzado con música de 'Brave heart' o 'Gladiator'.

Finalizado el vídeo apareció de nuevo la presentadora que invita a los asistentes a recibir unas clases prácticas de técnicas de motivación a cargo del actor Luis Zahera, hasta el momento sentado entre el público y que, de forma inmediata y en tono de comedia, comenzó a interactuar con los invitados ayudado, en un principio, por actores camuflados en el patio de butacas que intervinieron para romper el hielo. De repente salen a escena discutiendo los directores de marketing y ventas de la compañía. Comenzó un pequeño "gag” con Luis Zahera en el que se hizo partícipe al público. Fue uno de los momentos de mayor clima en la sala. La gente gritaba mensajes de optimismo, se levantaba, aplaudía: participaba. Los directivos abandonaron el escenario y el actor Luis Zahera introdujo otra de las sorpresas de la noche: el regalo de un viaje a Bali a los comerciales que han cosechado una mayor cifra de ventas.

El escenario cambió por completo a través del juego de luces, la música, la incorporación de sombrillas y palmeras y un vídeo que trasladó a todos los presentes a la paradisiaca isla de Bali. Durante la proyección, el actor Luis Zahera desapareció para dar paso a Remedios Cervantes con dos azafatas vestidas de balinesas y acompañadas de un pequeño atrezzo estilo balinés. La proyección concluyó con la iluminación de todo el escenario; era el momento de proclamar a los 50 afortunados mediante una voz en off e invitándoles a subir al escenario donde las azafatas balinesas les colocaban collares de flores.

Bajar a todos los premiados del escenario podía haber sido otro problema pero la agencia propuso y así se hizo otro 'sketch' divertido con el objetivo de que el desalojo de la escena fuera rápido. Fans mezcladas entre el público comenzaron a gritar de emoción y se abalanzaron sobre el escenario, falsos policías intentaban retirarlas. Entre todos consiguieron que los premia- 
dos volvieran de forma rápida a sus asientos.

Posteriormente, la música en directo comenzó a sonar desde el patio de butacas y los intérpretes del grupo Toom Pack iban incorporándose al escenario que, una vez más, había sido transformado en el tránsito de una escena a otra para incorporar los bidones y otros objetos que usa el grupo en su actuación.

Tras este acto, los invitados pasaban a la sala donde se serviría la cena, amenizada por una cantante de jazz que interpretó, como primer tema, una versión de la canción de Janes Choplin: Mercedes Benz. En el hall junto al auditorio el 'photocall' volvió a utilizarse como fórmula de entretenimiento mientras se cogían los ascensores para bajar a la zona de la cena. Mientras iban llegando y esperando al resto de invitados, se ofreció una copa de cava. Como bienvenida, en los lagos que forman las vistas de los ventanales de la sala, comenzó un espectáculo de fuegos artificiales aéreos y castillos formados con el mensaje de "sois los mejores”, la cifra '20.000', la estrella de Mercedes y la reproducción de uno de los modelos de furgonetas más vendidos.

El ambiente de la cena cambió por completo. Se trataba en ese momento de conseguir una velada algo más tranquila. La escenografía se reforzó con una iluminación indirecta, mobiliario de apoyo y grandes lonas, con la gráfica de la convención, que caía desde los balcones de la sala. En los cuartos de baño, los asistentes encontraron vinilos en los espejos y las paredes del aseo en la misma línea de mensajes y un efecto de sonido que hacía sonar aplausos cada vez que se abría o cerraba las puertas. Tras la cena, nuevo cambio para propiciar un ambiente más distendido donde el público pudo tomarse una copa mientras disfrutaba de la música de un Dj y bailarines subidos a unos pódium. Se trata de un ejemplo en el que el protocolo contribuyó a la fidelización de los empleados y constituyó una imprescindible herramienta de comunicación corporativa.

Un misterioso mensaje en una botella arrojada al mar Mediterráneo inició en mayo una travesía hasta las costas de Tarragona para ser leído en IX Encuentro con Grandes Clientes que Telefónica celebró del 16 al 18 de junio de 2009. Una reunión corporativa que bajo el lema ' 48 horas con Telefónica' combinó sesiones de formación, networking y actividades sociales y de ocio. El acto, organizado por la Unidad de Negocios de Grandes Empresas de la compañía, sitúa a los actos en una posición estratégica en las organizaciones por su poder comunicacional y por el valor que aportan a las empresas.

'48 horas con Telefónica' destacó por su gran originalidad e impacto, por una espectacular puesta en escena, un contenido muy cuidado, un desarrollo impecable y un claro compromiso con el medioambiente, aspectos todos ellos que aglutinan las principales características de los actos corpora- 
tivos como herramientas de comunicación estratégica de las organizaciones.

“Se puede predecir cómo viaja una botella en mar? ¿Podemos seguirla en tiempo real y conseguir que llegue a dónde nosotros queremos? Ése es el reto que nos hemos propuesto para celebrar la IX edición de 48 horas con telefónica, nuestra cita con grandes clientes que este año tendrá lugar en Tarragona”.

Con este original mensaje comenzaba el vídeo enlazado en la invitación electrónica que recibieron los grandes clientes que podían participar en el acto corporativo. Un mensaje dentro de una botella cuyo desplazamiento se podía seguir día a día en la página Web creada para la ocasión y gracias a un emisor GPS instalado en la botella.

En su primer intento la botella decidió ir en rumbo contrario y visitar las costas de Castellón. La organización se vio en la obligación de acudir a por la botella, la recogieron y volvieron a intentarlo tirándola en un punto más al norte, con la esperanza de que las corrientes y el viento ayudaran algo más que en el primer intento y en la seguridad de que la experiencia fallida y el nuevo intento revelaban también uno de los valores de la compañía: la perseverancia. Tras 20 días en el mar y más de 150 millas recorridas la botella "amarró" en la costa de Tarragona en la playa prevista, un final feliz que abría la puerta a otra incógnita ¿Qué contiene el mensaje?
El acto pretendía consolidar la imagen de liderazgo tecnológico e innovador de Telefónica, fidelizar fortaleciendo las relaciones institucionales y personales reuniendo a los máximos dirigentes del Grupo Telefónica con los Grandes Clientes, mostrar el papel de primer proveedor integrado del mundo y socio global y hacer de 48 horas el primer acto sostenible dentro de uno de los ejes de actuación de sostenibilidad del Grupo Telefónica. Se buscaba demostrar cómo las tecnologías de la información pueden ayudar a superar la crisis económica.

El número de invitados que asistieron a esta edición fue de 604. Su perfil, ejecutivos de alto nivel y con gran representación, un $80 \%$ hombres y un $20 \%$ mujeres. Se convocaron a los máximos representantes de los Grandes Clientes de Telefónica, con visión global de sus compañías y con poder de decisión (Consejeros Delegados, Directores Generales, Directores de Sistemas...) así como a la alta dirección del Grupo Telefónica y de la red comercial de Grandes Empresas a nivel global.

La invitación física fue sustituida por un mensaje digital, interactivo e innovador que mostraba alguno de los valores que el Grupo Telefónica quería trasladar interna y externamente: la sostenibilidad y la innovación. En el mismo correo recibían un login y un password para entrar en la página web creada para este acto y que se personalizaba para cada cliente. La página contemplaba las siguientes pestañas: programa del encuentro, sesiones de trabajo, 
actividades de ocio, registro y contacto. El programa de dos días de duración combinaba sesiones de trabajo, reuniones sectoriales con actividades sociales, lúdicas y de ocio.

El martes por la tarde, y tras el almuerzo en los distintos hoteles, se trasladaron al Palacio de Congresos de Tarragona, un espacio al que hay que entrar para descubrir una arquitectura excavada en la roca, para iniciar la primera sesión de trabajo cuya puesta en escena combinaba intervenciones, tecnología y mini espectáculos, todo ello presentado por la periodista Olga Viza. La historia de la evolución de la humanidad en un recorrido desde el presente hasta el Big-Bang, narrada a través de un impresionante espectáculo audiovisual, constituyó el hilo conductor del acto.

La escenografía estática se combinaba con fondos dinámicos y actuaciones en directo para recordarnos esa evolución de la humanidad. Materiales reciclables, utilización de LED para disminuir el consumo de luz $\mathrm{y}$, frente al habitual despliegue tecnológico en este tipo de actos corporativos, sólo se ubicó una pantalla en lona reciclable, utilizando la propia roca como pantalla natural de proyección en las distintas sesiones.

Del siglo XXI al BigBang, de lo moderno al inicio, del uso del láser y luz móvil a luz blanca y elementos estáticos. Al final, el BigBang reproducido a través de un audiovisual que recreaba la explosión que creó las estrellas y los planetas. El auditorio quedó oscuro: sólo se atisbaban puntos luminosos de luz blanca.

La primera sesión se abría con algo muy esperado por todos: el desenlace de la travesía realizada por la botella que contenía el misterioso mensaje. Las pantallas mostraban cómo la botella llegaba a la costa y era recogida por la misma persona que la puso a navegar que, a su vez, la entregaba a otra persona en la entrada del Palacio de Congresos para que ésta la condujera a la sala y se la diera a Olga Viza. Acompañada de una ambientación expectante la presentadora recogió el mensaje y leyó su contenido:

"No pretendamos que las cosas cambien, si siempre hacemos lo mismo. La crisis es la mejor bendición que puede sucederle a personas y países, porque la crisis trae progresos.

La creatividad nace de la angustia como el día nace de la noche oscura. Es en la crisis que nace la inventiva, los descubrimientos $y$ las grandes estrategias. Quien supera la crisis se supera a sí mismo sin quedar superado. Quien atribuye a la crisis sus fracasos y penurias, violenta su propio talento y respeta más a los problemas que a las soluciones. La verdadera crisis, es la crisis de la incompetencia.

El inconveniente de las personas y los países es la pereza para encontrar las salidas y soluciones. Sin crisis no hay desafíos, sin desafíos la vida es una rutina, una lenta agonía. Sin crisis no hay méritos. Es en la crisis donde aflora lo mejor de cada uno, porque sin crisis todo viento es caricia. 
Hablar de crisis es promoverla y callar en la crisis es exaltar el conformismo. En vez de esto, trabajemos duro. Acabemos de una vez con la única crisis amenazadora, que es la tragedia de no querer luchar por superarla”. Albert Einstein (1879 1955).

A partir de esta lectura nadie volvió a hablar de crisis, sí de optimismo.

La cena de gala se celebró el mismo día 16 de junio en el Parc Sarrá, a las afueras de Tarragona. Los invitados fueron rrecibidos por unos Castellers que armaron castillos humanos de hasta seis pisos. La inmortal comedia de Willian Shakespeare, "Sueño de una noche de verano", escrita en 1595, no sólo fue inspiración de innumerables artistas, también de la ambientación y el espectáculo que disfrutaron los invitados en esta cena prevista en el bosque, con música en directo, ninfas, seres mitológicos y bailarines aéreos que envolvían a los asistentes en un inolvidable sueño de una noche de verano. El argumento de la representación, al igual que en la obra de tan genial escritor, gira alrededor de seres mortales e inmortales que se enredan en historias equívocas a causa de una flor cuyo contacto hace que la gente se enamore de la primera persona que ve.

El final de fiesta lo protagonizó un espectáculo de luz y sonido, con proyecciones sobre agua. Según el gerente de Comunicación Comercial y Marketing Relacional de Telefónica España-Grandes Empresas, José María Palomares "pretendíamos bus- car algo que marcara un antes y un después. Buscábamos la máxima elegancia como respeto al cliente y valor de la compañía. A través de la representación que evoca un sueño onírico intentamos vivir una experiencia”.

La jornada del segundo día comenzó con otra sesión de trabajo para continuar con una amplia gama de actividades de ocio, de libre elección y muy diversificadas para dar posibilidades a distintos gustos. En este tipo de actos corporativos, las actividades de ocio son de suma importancia ya que generan relaciones muy especiales entre las personas y extraordinarios climas de complicidad.

La cena de clausura buscó, según la organización, "resaltar la diversidad iberoamericana latente en Telefónica así como el aspecto internacional de la misma”. Se eligió la Cantina Mexicana de Port Aventura y el catering propio de este parque temático. Al ritmo de las habaneras y bossa nova, la cena terminó con la premiación de las competiciones desarrolladas en las actividades de ocio y un espectáculo de tango acrobático.

Esta edición afrontaba un gran reto: convertirse en el primer gran acto sostenible de Telefónica. Para ello el acto se enfocó en dos direcciones: la reducción del consumo de materias primas (luz, papel, agua) y la compensación de las emisiones de $\mathrm{CO} 2$ generadas por el acto (traslados, actividades, reunión de trabajo), a través de un proyecto que está certificado por la Funda- 
ción $\mathrm{CO} 2$ y que revertirá en la construcción de una pequeña central hidroeléctrica en Nicaragua. La comunicación con los invitados se realizó a través de una Web específica, gráfica ligera y una carta de información del estudio y compensación por las emisiones de $\mathrm{CO} 2$.

Tras la finalización del acto se creó una Web post acto a través de la cual los asistentes podían descargar desde las presentaciones realizadas en las sesiones de trabajo a imágenes y vídeos de las sesiones de trabajo y de las actividades sociales y de ocio. Uno de los aspectos más destacables de esta Web es el cuestionario de valoración que debían rellenar los asistentes y en el que se preguntaba sobre la valoración general del encuentro, su utilidad, valoración especifica de las sesiones de trabajo y de los ponentes con posibilidad de realizar comentarios al respecto y la valoración detallada de la organización y de las actividades de ocio.

\section{Conclusiones}

Todo no comunica por sí mismo, hay que acompañarlo de acciones y compromisos, de principios éticos, para que tenga repercusión en la reputación y visibilidad de la organización. El concepto de 'protocolo' ha evolucionado notablemente en los últimos años y ha dejado de entenderse como una sencilla técnica para disponer a los invitados en un acto, para convertirse en uno de los ejes fundamentales en el diseño y ejecución de las acciones de comunicación interna y externas de las organizaciones. La literatura científica sitúa ya al pro- tocolo al mismo nivel que las tradicionales acciones de publicidad y le confiere un papel preponderante en la estrategia de comunicación de las empresas e instituciones.

Como se ha expuesto más arriba, los actos comunican, trasladan la imagen, el estilo y la responsabilidad social empresarial o corporativa de una organización. Por esa razón, el protocolo se erige en una herramienta estratégica en la comunicación organizacional.

\section{Referencias}

ÁLVAREZ, M ${ }^{a}$ L. (2008) Nociones de protocolo desde la bibliografía de sus autoridades. Tesis doctoral dirigida por Daniel Martí. Facultad de Ciencias Sociales y de la Comunicación. Universidad de Vigo.

ÁLVAREZ, Ma L. (2008) El léxico del protocolo. En ICONO 14, Revista de Comunicación y Nuevas Tecnologías. Madrid
CAMPOS, G. (2008). Producción de actos. La puesta en escena del protocolo. Ediciones Protocolo. Madrid

DICCIONARIO DE LA REAL ACADEMIA

ESPAÑOLA. Vigésima segunda edición.

FREEMAN, R.E (1984). Strategic Management: A

Stakeholder Approach. Pitman 
FUENTE, C. (2007). Protocolo para actos. Técnicas de organización de actos. Ediciones Protocolo. Madrid.

HERRERO, J.C. y FUENTE, J.L. (2004) El tratamiento de los medios en la organización de actos. Ediciones Protocolo. Madrid.

MARÍN, F. (2000). Protocolo y comunicación: los medios en los actos públicos. Bayer hermanos y Compañía S.A. Madrid.

MARTÍ, D. (2007). Comunicación y Protocolo, perspectivas teóricas en ICONO 14, Revista de Comunicación y Nuevas Tecnologías. Madrid

MÍNGUEZ, N. (1999). Un marco conceptual para la comunicación corporativa. Revista ZER. Universidad del País Vasco. Núm. 7. Diciembre de 1999.

OTERO, M M T. (1999) Protocolo y Relaciones Públicas de Estado: los días nacionales en la exposición universal de
Sevilla 1992. Tesis doctoral dirigida por Juan Rey Fuentes. Facultad de Ciencias de la Información. Universidad de Sevilla.

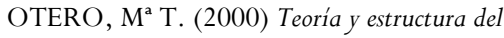
ceremonial y el protocolo. Sevilla : Mergablum

PUMAR VÁZQUEZ, J (1995). Ceremonial e Protocolo. IR INDO Editions. Santiago de Compostela.

ROFRIGUEZ, A. (2004) Protocolo y Ceremonial en las Fuerzas Armadas. Ediciones protocolo. Madrid

SIERRA, J. (2007) Protocolo: símbolos y comunicación el siglo XXI. Tesis doctoral 2005. Dirigida por Francisco García García. Departamento de Comunicación Audiovisual y Publicidad II. Universidad Complutense. Madrid.

\section{Cita de este artículo}

CÉSAR HERRERO, J. y CAMPOS GARCÍA DE QUEVEDO, G. (2010) El necesario protocolo en la comunicación organizacional. Revista Icono14 [en línea] 1 de Julio de 2010, Año 8, Vol. 2. pp. 182-202. Recuperado (Fecha de acceso), de http://www.icono14.net 